\title{
Parametric Estimate Cost of Wind Farms in Latin America and the Caribbean
}

\author{
L. A. Enríquez García ${ }^{1}$, L.J. García Faure ${ }^{2}$, C.S. Oro Ortíz ${ }^{3,}$ J.R. Muñoz Cargua ${ }^{4}$ \\ ${ }^{1}$ ESPOCH, MINEDUC, Riobamba, Ecuador. \\ ${ }^{2}$ CEER, U.O, Santiago de Cuba, Cuba. \\ ${ }^{3}$ CEER, U.O, Santiago de Cuba, Cuba. \\ ${ }^{4}$ ESPOCH, Riobamba, Ecuador.
}

\begin{abstract}
In order to be able to carry out early studies of viability, to analyze variants and to make tests of sensibility to the projects of wind farms, in this work has been developed a mathematical model for a quick, economic way and with enough precision, determine the cost that will have the park later when it is built. The method receives the name of parametric estimate of the cost. It consists on mathematics relationships between the variables or controllers (drivers) of the cost of projects. Although in the independent evaluations, the results might not be as exact as in the discrete methods, it presents a high relative precision when they are compared alternative, and their property of continuity allow him to work inside a calculation algorithm for the analysis of variants and sensibility where the technical and economic variables of the project are involved. It was developed and evaluated for the countries of Latin America and the Caribbean by the particular characteristics that exposed in the work with regard to other regions of the world.
\end{abstract}

Keywords: Capital cost of wind farms, equation, parametric cost estimate.

\section{Introduction}

Engineering today is not limited to the solution of problems in their respective fields of knowledge, but takes into account all the variables that can affect the application of solutions and development projects. One of those variables are the cost, which allows analysis of alternatives, take decisions and change solutions related to the project. This is because the effectiveness of the projects is usually evaluated in economic terms where costs and income are the key variables. It is almost impossible to separate the technical from the economic.

The different elements that make up the cost of the life cycle of a project are well defined, and its calculation should not have difficulties if those costs are separately and performed with discrete values. The problem occurs when there is a need to establish the continuous relationship between the cost and the basic parameters of the process. When the independent variables and the cost are enlisted in a decision algorithm, analysis must be consistent with both.

In practice, the determination of the cost of the investment or capital cost can be performed by two general procedures: step-by-step or discrete direct determination and the determination by some method of estimation.

The discrete calculation of the cost of projects normally done by the sum of the individual costs of engineering, equipment, materials and work within the capital cost. The parties may vary in size and number from a few to hundreds or thousands of tasks or discrete work packages. This calculation isusually carried out by the contractor and accompanied by the programming of each activity. The result may be necessary if all the determinants of the cost are dominant but are laborious, time-consuming work and do not disclose the relationship between the technical parameters and cost.

There are different methods of estimation of the capital cost, some of them can be applied during the early stages of the project in which only need to have an idea of the cost; others may be as accurate as the discrete calculation. This paper presents the methodology followed for the development of a mathematical model for parametric estimation of the cost of wind farms for the specific conditions of Latin America and the Caribbean.

Parametric Cost Estimation-Volume4 the cost of NASA manual defines the parametric estimation by a technique that employs one or more relations (RCE) cost estimation, mathematical and logical, relations, which are used in engineering to calculate the cost associated to the project, the manufacture or modification of as pecificelement.[1]

The estimate is based on aspects of technical, physical or other characteristic element. This definition establishes the clear link between the cost and the technical parameters of the finished product. The parametric technique emphasizes controlling questions of cost (drivers), as power, capacity, size, weight, thrust, etc., not over the irrelevant details. It is foundation have an origin in two fundamental principles: the law of economic 
scale and the theory of learning (The learning Theory). The first establishes the relationship between cost and capacity (or power, torque, power, etc.), which in its most basic form is expressed through the theory of sixtenths (Sixtenth Theory) [2]; the second establishes the relationship between the cost, and the number of units produced and the experience gained through the activity.

\section{Materials And Methods}

The procedure for the development of the mathematical model of the parametric estimate of the cost of wind farms is:

1. Establishment of hypotheses.

2. Model formulation and definition of cost drivers.

3. Development of relations of estimate and cost indices.

4. Adjustment and evaluation model

Hypothesis- As a hypothesis, that the relations of cost estimation (RCE) are formed by the following variables: power of the Park $(\mathrm{P})$, number of turbines $(\mathrm{N}),(\mathrm{Z})$ hub height. It is evident that the total cost increases as the power, the number of machines and the height of the bucket in machines of equal power at the cost of the additional material consumed and the increase of the resistance of the Tower; many manufacturers give the option of the same machine with different heights of the towers. However, when increasing the height of the bucket is made by the increase of the rotor diameter for increased power, the latter exerts greater influence on the increase in the cost. They also have influence on the total cost of the Park, the increase of power that needs to be done to offset the decrease in air density with altitude of the location and the effects of learning and rates of inflation, which tend to be countered.

Model formulation-the mathematical model for parametric estimation can be given using the following general expression:

$$
\mathrm{C}=\mathrm{A} \cdot \prod_{\mathrm{i}=1}^{\mathrm{n}}(\mathrm{REC})_{\mathrm{i}}^{\mathrm{a}_{\mathrm{i}}} \cdot \prod_{\mathrm{j}=0}^{\mathrm{m}} \mathrm{I}_{\mathrm{j}}
$$

In which:

A - Characteristic coefficient.

$(\mathrm{RCE})_{\mathrm{i}}-$ Relationships of cost estimation.

$a_{\mathrm{i}}-$ Exponent of the respective REC.

$\mathrm{I}_{\mathrm{j}}-$ Cost indices.

The coefficient A is can estimate the approximate analytical procedures, but is influenced by external factors and the interrelation of variables, as you can see, by which its final value is obtained as a result of the adjustment of the model with the experimental values supplied. It cost rates are tools of cost adjustment for changes over time and in combination with appropriate local factors. Cost rates may be several depending on the level of refinement that you want to achieve in the model. A typical example of cost index is that allows you to adjust the present cost data from the past through the learning curve. The AACE (Notebook 39) describes the main sources of indexes of cost [3].

Development of the RCE and cost indices-The relationship between the costs of the wind farm planned (with subscript 2) and a wind farm (with subscript 1) with altitude above the level of the sea, standard density the air pattern of $1,225 \mathrm{~kg} / \mathrm{m} 3$ and unitary power, number of machines and the hub height parameters can be set:

$$
\left(\frac{\mathrm{C}_{2}}{\mathrm{C}_{1}}\right)=\left(\frac{\mathrm{P}_{2}}{\mathrm{P}_{1}}\right)^{\mathrm{a}} \cdot\left(\frac{\mathrm{n}_{2}}{\mathrm{n}_{1}}\right)^{\mathrm{b}} \cdot\left(\frac{\mathrm{Z}_{2}}{\mathrm{Z}_{1}}\right)^{\mathrm{c}} \cdot\left(\frac{\rho_{0}}{\rho}\right) \cdot \mathrm{I}_{\mathrm{T}}
$$

Where:

$$
\begin{aligned}
& \left(\frac{\mathrm{P}_{2}}{\mathrm{P}_{1}}\right)^{\mathrm{a}} ;\left(\frac{\mathrm{n}_{2}}{\mathrm{n}_{1}}\right)^{\mathrm{b}} ;\left(\frac{\mathrm{Z}_{2}}{\mathrm{Z}_{1}}\right)^{\mathrm{c}}-\text { Controlling relationships of power, number of machines, and the hub height. } \\
& \left(\frac{\rho_{0}}{\rho}\right)^{-} \text {- The index of cost for the variation of density with altitude. }
\end{aligned}
$$


Being: $\rho 0$ and $\rho$ the density of air at sea level and the height $\mathrm{H}$ respectively. $I_{T}$ - Rates that take into account the factor time in cost.

Unit values of $\mathrm{C} 1, \mathrm{P} 1, \mathrm{n} 1$ and $\mathrm{Z} 1$ gets $\mathrm{A}$ common coefficient, being the cost estimation equation follows:

$C=A \cdot P^{a} N^{b} \cdot Z^{c} \cdot I \rho \cdot I_{T}$

Model fit-Model fit- to determine A common ratio and the exponents a,b and c which fit the model, a sample was taken at random from 22 parks of tens of countries. Latin Americans with the greater use of wind power, which represents more than $25 \%$ of the parks operating in 2013, considered year first for the purposes of the time index. Taking the equation (3) to a linear model (could have used a professional software) in order to determine using a lineal estimation in Excel worksheet the exponents a. b, c and the coefficient to. It had the following values: $\mathrm{a}=0,65 ; \mathrm{b}=0,928 ; \mathrm{c}=1,77$ and $\mathrm{A}=18,06$, then, the resulting equation is given by:

$C=18,06 \cdot P^{0,65} N^{0,928} \cdot Z^{1,77}$

Index of change in the density of the air-Index of change in the density of the air- Machine's power is proportional to the density of the air, and it depends on atmospheric pressure and temperature according to the ideal gas law. Pressure decreases with altitude, and even though the temperature may decrease, their influence is minor and therefore, the density decreases with altitude. To compensate for the decrease of the power density, it must be extra power with a consequent increase in the cost of the Park; this effect taken into account in the equation of estimation by the density index:

$I_{\rho}=\left(\frac{1,225}{\rho}\right)$

Learning index- Experience has shown that when an activity is repeated, decreases the time to carry out such activity and measures that increases the quantity of the produced object, reducing their cost of production. [4]These factors have been shown in wind-power generators industry, where, despite the inflation rate, the cost of wind turbines and wind farms shows decreasing trends as shown in Figure 1. There is full agreement on the behavior of Chinese, European wind turbines and North American $[5,6]$, so this job has been deducted index global scheduling from those behaviors.

$$
I_{t}=(t)^{-0,05}
$$

Equation (4) is definitely:

$C=18,06 \cdot P^{0,65} N^{0,028} \cdot Z^{1,77} \cdot(t)^{-0,05} \cdot\left(\frac{1,225}{\rho}\right)$

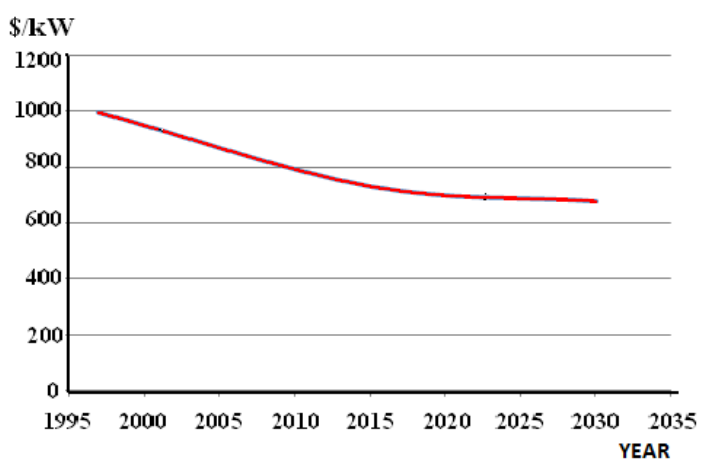

Figure 1. Trend of decrease in the cost of the parks over time. (Data from CWEER 2013 and EWEA 2013)

\section{Results And Discussion}

Statistics equation- The statistical analysis shows the following results:

Regression coefficient $r^{2}=0,985$

Standard deviation of the error $\sigma=7,8 \%$

Averagecostof 5\% error

F. calculated $=888,93$

$\mathrm{Df}=18$ for $\mathrm{n}=22: \mathrm{V}_{1}=3 ; \mathrm{V}_{2}=18$ 
F. Tabulate [7] $=6,09$ for $\alpha=0,01$

F. Calculated $\gg>$ F. Tabulate; therefore, it is unlikely that the calculated $\mathrm{F}$ value occurred by chance.

The verification of the required size of sample with values of $\sigma=0,078$; error average of $5 \%$ and a confidence level of $99 \%(\mathrm{Z} 0=2,58)$, indicate that:

$n=\frac{Z_{0}^{2} \cdot N \cdot \sigma^{2}}{e^{2}(N-1)+Z_{0}^{2} \cdot \sigma^{2}}=\frac{2,58^{2} \cdot 78 \cdot 0,078^{2}}{0,05^{2} \cdot(78-1)+2,58^{2} \cdot 0,078^{2}}$

$n=13,58=14$

In other words, would have been enough a sample of 14 parks. The equation obtained from the fundamental parameters of the Park, highlights the relationship that each of those parameters in the cost of the project. It is a grave mistake when the estimate of cost is carried out with an average value of the specific cost $(\$ / \mathrm{kW})$ independent of the number of machines, their power or the height of the cube, because a park will have different capital cost depending on the combination that is adopted for these parameters. Below illustrates the influence that has each of the parameters in the cost of the Park. In Figure 2, it is observed that the specific costs of the Park $(\$ / \mathrm{kW})$ decrease as it increases the power of the machines while maintaining the hub height and the number of constant machines. This is explained through the law of scaling economic by having one lower exponent one.

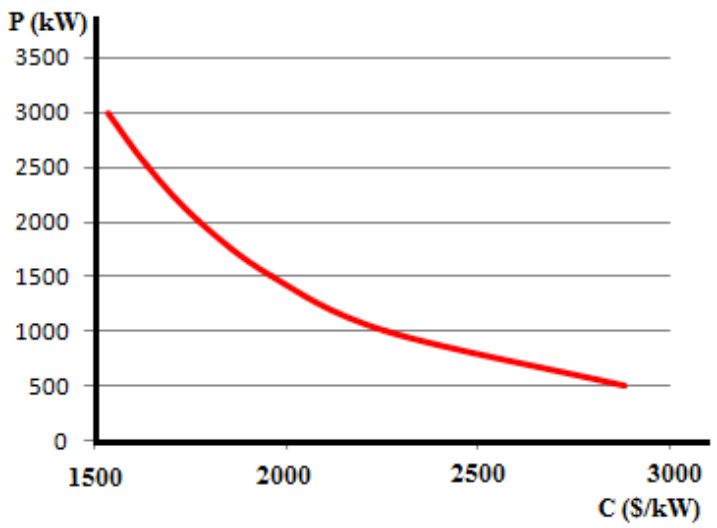

Figure 2. Decreased specific cost with the power of the machines.

With the increase in the number of machines in the Park power, increases the specific cost, as shown in Figure 3. This is because with one larger number of machines, the power of these decreases, but not on a proportional basis, so the specific cost of the Park increases, moreover, with one greater number of machines increases the cost of auxiliary equipment.

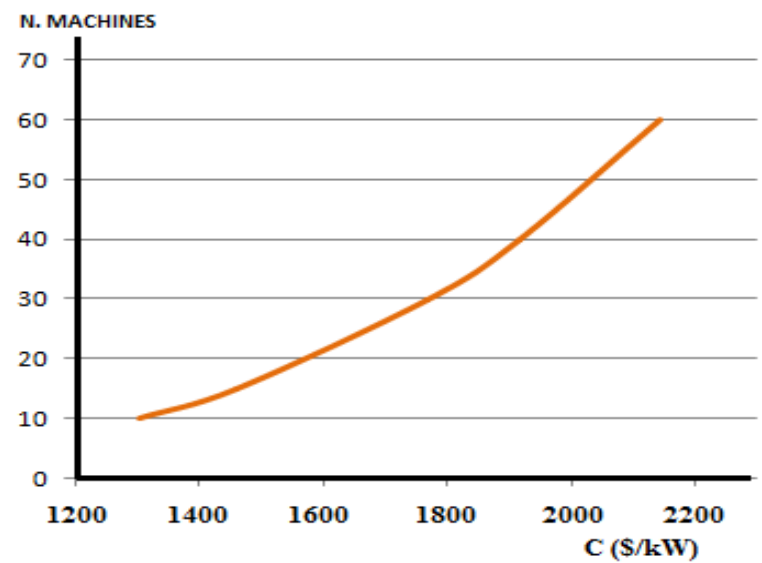

Figure 3. Increasing the specific cost of the park with the number of machines.

If he is kept constant across the number and power of the machines and the hub height is varied, the specific cost of the Park increases according to a law of exponential with exponent greater than unity, as you can see in Figure 4. The cost with the height increase is explained by the amount of material consumed, in addition, each additional meter must be stronger than the previous one, reason why the exponent of the cost with the 
height is greater than the unit. The increase of the cost with the height is justified by the increase that achieved the speed of the air, and the energy recovered.

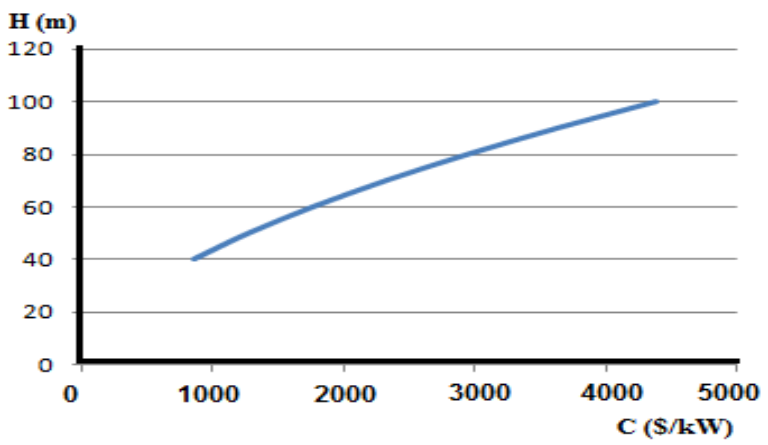

Figure 4. Increasing the specific cost of the park with hub height.

The interaction of the above parameters is made clear when discussed a park with different structures, as the following example:

\section{Structure 1:}

Power of the Park: $51 \mathrm{MW}$

Power machines: $1.5 \mathrm{MW}$

Machines number: 34

Hub height: $80 \mathrm{~m}$

\section{Structure 2:}

Power of the Park: $51 \mathrm{MW}$ machines power: 1MW machines number: 51 hub height: $80 \mathrm{~m}$

Both to be built in the year $2016(t=4)$ and density of air (near sea level) 1.2. Applying equation (7) corrected with costs rates by time and density, the cost estimated in both cases are the following:

Structure 1: \$120 435849

Structure 2: \$134 805977.

In analysis that must be done now is as follows: which of the two parks is more profitable?

The answer to this question is obtained by a comprehensive analysis of economic and financial profitability, where the utilization factor having the Park plays an important role in the energy produced.

\section{Conclusions}

From two basic principles: the theory of economic scale and learning theory was developed an equation to estimate the capital cost of wind farms based on the basic parameters of the project and their correction via indexes for particular site conditions or when it is executed. The equation obtained was evaluated with a significant sample of parks in Latin America and the Caribbean by the particular characteristics that occur in this region compared to other regions of the world. The statistical results of the validation demonstrate the confidence level of this equation.

This equation also ensures an early estimate of the cost of the project, to determine the most appropriate variant in each case and if used as an element within an optimization algorithm to determine simultaneously the technical and economic variables that optimize the objective function.

Based on two basic principles: the theory of the scaling economic and the learning theory was developed an equation that allows you to estimate the capital cost of wind farms on the basis of the basic parameters of the project and its correction using indexes for the particular conditions of the site or the time in which it is executed. The equation obtained was evaluated with a significant sample of parks in Latin America and the Caribbean by the particular features arising in this region to other regions of the world.The statistical results of the validation show the level of trust of this equation.

\section{References}

[1]. NationalAeronautic and Space Administration. NASA Cost Estimating Handbook.V-4.USA, September/2014

[2]. Joseph W. Hamaker. The History of NASA Cost Estimating. NASA Cost Estimating Web Site. 2002

[3]. LelandBlank, Anthony Tarquin. Ingeniería Económica. Mc Graw Hill.Bogotá, Colombia. 2002

[4]. International Society of Parametric Analysis ISPA SCA. Parametric Estimating Handbook.FourthEsition. Vienna, 2008

[5]. EWEA.The European Wind Energy Association, EWEA. The Economics of Wind Energy, March/ 2009.

[6]. Chinnesse Wind Energy Economic Review CWEER 2013 
[7]. Jorge C. Canavos. Probabilidad y Estadística. Aplicaciones y Métodos. Mc-Graw Hill Interamericana. México 1998 